\title{
Clinical Feature and Mutation Analysis of Glutamate Dehydrogenase (GLUD1) in Three Chinese Patients with Congenital Hyperinsulinism
}

\author{
Mei-ting Chen, Tong Wang, Shi Chen, Jiang-feng Mao, Miao Yu and Xin-hua Xiao* \\ Department of Endocrinology, Peking Union Medical College, China
}

Submission: November 14, 2017; Published: January 25, 2018

*Corresponding author: Xin-hua Xiao, Department of Endocrinology, Key Laboratory of Endocrinology, Ministry of Health, Peking Union Medical College Hospital, Diabetes Research Center of Chinese Academy of Medical Sciences \& Peking Union Medical College, \#1 Shuai-Fu-Yuan, Wang-Fu-Jing, Beijing, 100730, China, Email: xiaoxh2014@vip.163.com

Abstract

Aim: To summarize the clinical feature and analyze the gene mutation for three pediatric patients with congenital hyperinsulinism (CHI) and hyperammonemia (HA).

Methods: Three Chinese pedigree of CHI-HA in Peking Union Medical College Hospital from 2009 to 2012 was analyzed for the clinical features and laboratory data. DNA sequencing was performed to identify mutation in ATP binding cassette subfamily C member 8 (ABCC8), potassium voltage-gated channel subfamily J member 11 (KCNJ11), glutamate dehydrogenase 1 (GLUD1), glucokinase (GCK) and INS gene in the pedigree.

Results: Besides CHI-HA, all patients suffered various degree of neurodevelopment disorders, with mean birth weight of $3.15 \mathrm{~kg}$ and delay onset of 6.0 months at average. Two patients presented mutation of c.1493 C>T (p. S498L) in exon 11 and one patients confirmed mutation of c.968 G>A (p.S269H) in exon 7 in GLUD1 gene. We did not detect any mutation inABCC8, KCNJ11, GCK, and INS genes. Leucine limited dietary therapy and diazoxide were responsive for all patients.

Conclusion: GLUD1 mutation was one common cause of CHI-HA and early molecular diagnosis was of great importance.

Keywords: Congenital hyperinsulinism; Hyperammonemia; DNA mutation analysis; Glutamate dehydrogenase

\section{Introduction}

Congenital hyperinsulinism (CHI), or persistent hyperinsulinemic hypoglycemia of infancy (PHHI) is a genetically heterogenous disease with mutation of eleven genes (ABCC8, KCNJ11, GLUD1, GCK, HADH, HNF1A, HNF4A, SLC16A1, UCP2, HK1, PGM1) [1,2]. Gain of function mutation of GLUD1 is the second commonly seen genetic defect for $\mathrm{CHI}$, characterized by hyperinsulinemia-hyperammonemia (HIHA) syndrome [3]. GLUD1 mutation can be sporadic de novo mutation or inherited in autosomal dominant pattern. Phenotype of GLUD1 includes relative mild symptomatic hypoglycemia and leucine sensitive insulin secretion as well as asymptomatic hyperammonemia [3].

GLUD1 encodes the intramitochondrial enzyme glutamate hydrogenase (GDH), of which the common mutation locus includes allosteric GTP binding domain (exon 11 and 12), catalytic domain (exon 6 and 7) and antenna-like structure (exon 10) [4]. GDH is involved in glucose-stimulating insulin secretion by catalyzing glutamate to $\alpha$-ketoglutarate and ammonia, finally generating ATP to trigger insulin release in pancreas $\beta$ cells. GDH can be activated by ADP and leucine and inhibited by GTP and ATP at normal physiological condition. Gain of function mutation results in excessive secretion of insulin by activating GDH via decreasing the sensitivity for GTP. Also, lack of a glucagon response was found in alpha cells in impaired counter-regulation of hyperinsulinism via mitochondrial GTP signal pathway generated by GDH in $\beta$ cells, contributing to symptomatic hypoglycemia [5].

Thus, children with GLUD1 mutation often have recurrent symptomatic hypoglycemia and persistent asymptomatic hyperammonemia. The phenotype is usually associated with normal birth weight, delayed age of presentation and higher risk of seizure compared to other subtypes of $\mathrm{CH}[4,6]$. Excessive release of ammonia can also be detected in patients with GDH mutation, which usually elevated $3 \sim 8$ times than upper limit of normal [7]. Fortunately, most of patients were responsive to diazoxide and could alleviate by protein-limit diet [4].

In recent years, some articles reported mutation analysis for GLUD1-HIHA, which focused on mutation in exon 6,7,10,11 and 12 [8-11]. Our aim was to analyze clinical character and genome 
mutation for three pediatric patients with HIHA and provide more evidence for genetic diagnosis and treatment in the future.

\section{Materials and Methods}

\section{Ethical approval}

The study was conducted in accordance with the Declaration of Helsinki and was approved by the institutional review board of Peking Union Medical College Hospital. Informed written consent was obtained from all patients before their enrollment in the study.

\section{Patients}

We enrolled three patients diagnosed with glutamate dehydrogenase congenital hyperinsulinism in department of endocrinology, Peking Union Medical College Hospital (PUMCH) from December 2007 to December, 2012. The diagnostic criteria included detectable concentration of insulin and/or C peptide in serum when blood glucose is lower than $3 \mathrm{mmol} / \mathrm{L}$, with inappropriately low concentration of free fatty acids and ketone bodies $[6,12]$. After diagnosis of CHI was made, patients were treated with protein-limited diet at first. Two patients treated with diazoxide and protein-limited diet. One patient was treated by leucine limited diet alone. Peripheral blood samples $(3 \mathrm{ml}$, EDTA-anticoagulant tube) were collected from each patient.

Genomic DNA was extracted from peripheral leukocytes using whole blood genome DNA Rapid Extraction Kit (Biomed Co. Ltd, Beijing, China) according to the manufacturer's instructions. Mutation analysis was conducted using polymerase chain reaction (PCR), and PCR products were sent to Sino Gene Max Co. Ltd, Chinese National Human Genome Center (Beijing, China) for direct DNA sequence analysis. Sequencing reactions were analyzed on the Applied Biosystems 3730x IDNA Analyzer and compared with published sequences using online database of University of California, Santa Crus (http://genome.ucsc.edu/ cgi-bin/hgBlat).

The primers to amplify the ABCC8, KCNJ11, GLUD1, GCK, and INS gene sequences were designed by the Primer 5.0 software. The sequence of the primers is listed in Supplementary Tables. The patients were screened for mutations in the 39 exons of
ABCC8 gene; the untranslated regions and the exon of the KCNJ11 gene; the $6,7,8,10,11,12$ exons of GLUD1gene; 10 exons of the GCK gene; and the 1,2 exons of INS gene. The primer sequence for PCR referred to Supplement Table 1. We searched for single nucleotide polymorphism (SNP) in database of dbSNP137, 1000 Genomes and human Exome Aggregation consortium (ExAC). We also searched for reported mutation in human genome mutation database (HGMD). The effect of amino acid substitution on protein function was predicted using Mutation Taster (http:// www.mutationtaster.org/), SIFT

(http://sift.jcvi.org/www/SIFT_BLink_submit.html) and Polyphen-2 (http://genetics.bwh.harvard.edu/pph2/) bioinformatic tools. All gene mutational analyses were performed for participants.

\section{Results}

\section{Patient demographics}

Basic information for three eligible participants was shown in Table 1. All three patients were Han Chinese. Patient 1 and 2 came from northern China while Patient 3 was from the southern. All patients suffered from protein-sensitive hypoglycemia and asymptomatic hyperammonemia. Patient 1 and 3 presented convulsion and cyanotic lip. Patient 1 developed frequent unconscious and extremity convulsion, who was later confirmed partial epilepsy by electroencephalogram (EEG). Patient 1 presented delay development with mental retardation and speechless at the age of two years. Patient 2 presented muscular fasciculation at extremities and declined attention at one-year old and then developed mental retardation five years later. Patient 3 had recurrent convulsion and cyanotic lips for one weeks and fortunately received protein-limited diet and diazoxide treatment in hospital. Patient 3 was additional exanimated mild communicating hydrocephalus and right frontal subdural effusion by cranial computed tomography. EEG was conducted for patient 2 and 3 , and revealed normal results. Parents of all three patients were healthy, denying family history of hypoglycemia. Grandfather and great-grandmother of patient 2 suffered from diabetes at the age of fifty. Pedigrees of three patients were shown in Figure 1(Supplement Table 1).

Table 1: Demographics and mutation analysis of three pediatric patients with $\mathrm{CHI}$.

\begin{tabular}{|c|c|c|c|c|c|c|c|c|c|c|c|}
\hline $\begin{array}{c}\text { Patient } \\
\text { number/ } \\
\text { Gender }\end{array}$ & $\begin{array}{c}\text { Age of } \\
\text { presentation } \\
\text { (months) }\end{array}$ & $\begin{array}{c}\text { Birth } \\
\text { weight } \\
\text { (kg) }\end{array}$ & $\begin{array}{c}\text { Blood } \\
\text { Glucose } \\
\text { (mg/ } \\
\text { dL) }\end{array}$ & $\begin{array}{c}\text { Blood } \\
\text { insulin } \\
(\mu \mathrm{IU} / \\
\mathrm{mL})\end{array}$ & $\begin{array}{c}\text { Blood } \\
\text { insulin } \\
(\mu \mathrm{IU} / \\
\mathrm{mL})\end{array}$ & $\begin{array}{l}\text { Convulsion? } \\
\text { Epilepsy? }\end{array}$ & $\begin{array}{l}\text { Diazoxide } \\
\text { treatment }\end{array}$ & Exon & nt change & $\begin{array}{c}\text { AA } \\
\text { change }\end{array}$ & $\begin{array}{c}\text { Parent of } \\
\text { origin }\end{array}$ \\
\hline $1 / \mathrm{F}$ & 2 & 3.25 & 2.1 & 49.3 & 127 & Yes/Yes & No & 11 & c. $1493 \mathrm{C}>\mathrm{T}$ & p.S498L & De novo \\
\hline $2 / \mathrm{M}$ & 12 & 3 & 2.3 & 80.63 & 114.1 & Yes/No & No & 7 & c.978G $>A$ & p.R269H & $\begin{array}{c}\text { De } \\
\text { novo or } \\
\text { maternal }\end{array}$ \\
\hline $2 / \mathrm{M}$ & 12 & 3 & 2.3 & 80.63 & 114.1 & Yes/No & No & 7 & c. $978 \mathrm{G}>\mathrm{A}$ & p.R269H & $\begin{array}{c}\text { De } \\
\text { novo or } \\
\text { maternal }\end{array}$ \\
\hline
\end{tabular}

F: female; M: male; Blood insulin and ammonia concentration were determined at the presence of hypoglycemia respectively. Nt (nucleotide) and $A A$ (amino acid) change indicated nucleotide codon position numbering. 


\section{Journal of Endocrinology and Thyroid Research}

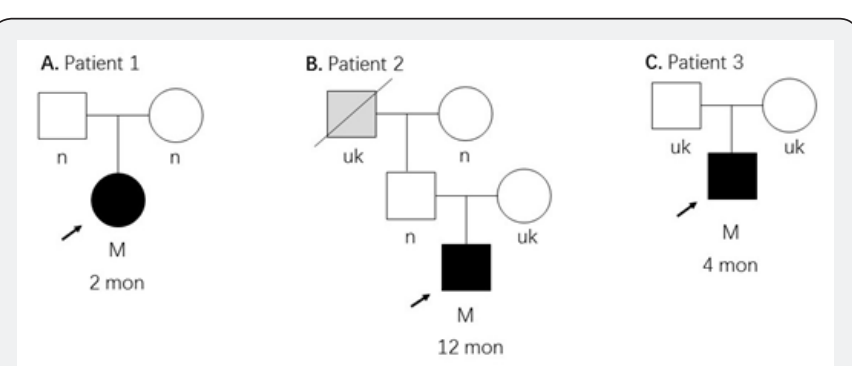

Figure 1: Pedigrees of the three families (A, patient 1; $B$, patient 2; C, patient 3) with GLUD1 mutations. (n, Normal allele; $M$, mutation; uk, unknown genetic allele). Gray filled shapes represent patients with diabetes and the onset of diabetes were at the age of fifty. White filled shapes represent normal participants while black filled shapes represent $\mathrm{CHI}$ patients. Age at disease onset are shown below the symbols.

After CHI-GD diagnosis was made, one patients alleviated by leucine-limited diet and two patients was treated with diazoxide $5 \mathrm{mg} / \mathrm{kg} \mathrm{d}^{-1}$. The leucine limited diet was design by experienced nutritionist in PUMCH. Both patient 1 and 3 were responsive to diazoxide. For patient 1, his fasting blood glucose level ranged 4.0 to $5.0 \mathrm{mmol} / \mathrm{L}$, and postprandial blood glucose ranged 4.4 to $5.5 \mathrm{mmol} / \mathrm{L}$ after $50 \mathrm{mg}$ diazoxide administration twice a day in combination of leucine limitation diet. And the fasting blood glucose was $4.4 \mathrm{mmol} / \mathrm{L}$ after $5 \mathrm{mg}$ diazoxide administration once a day for patient 3 . For patient 2, we designed several leucine limitation diets and found the diet with leucine 16mg (sugar free yogurt $125 \mathrm{ml}$, beef $5 \mathrm{~g}$, carbohydrate $50 \mathrm{~g}, 212 \mathrm{kcal}$ in total)

Supplement Table 1: Primers for GLUD1 gene analysis.

\begin{tabular}{|c|c|c|}
\hline Exon & Primer Sequence & Reverse sequence \\
\hline 6 & 5' TACATTCATACACACACTCCTA 3' & 5'TGATAGTTTGGTTGAAGTTGGT3' \\
\hline $7 \sim 8$ & 5' CCAGGACTTTAATTTTTGTGTT 3' & 5' ATTGATAATGTTGGTTCTGGTT 3' \\
\hline 10 & 5'TGGGATGGGAAGGAGTGTTA3' & 5'AGATGAGTTTTGGCGAACAAGA3' \\
\hline 11 & 5'TTCTGTTAGCAATATCTTGATCTCTTG3' & 5'ACACACATGTCACGCACTTAC3' \\
\hline 12 & 5'ACAGGGACACAAAGCAGGTC3' & 5'ACAGTCTGGCGGCTGAGATAG3' \\
\hline
\end{tabular}

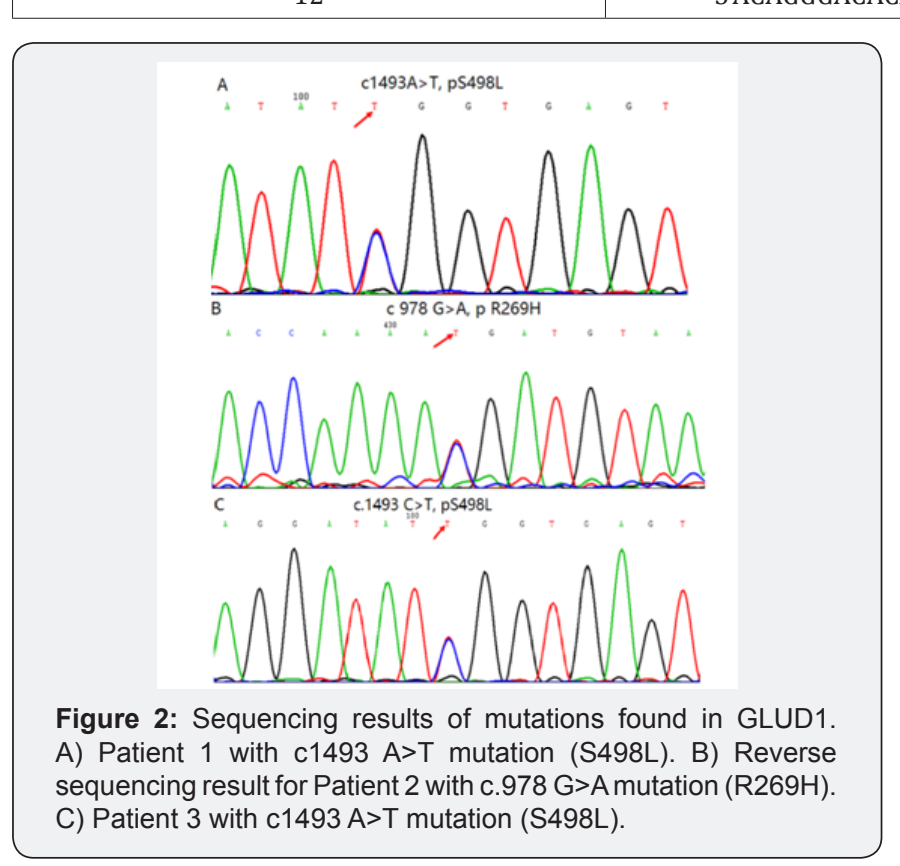

Figure 2: Sequencing results of mutations found in GLUD1. A) Patient 1 with c1493 A>T mutation (S498L). B) Reverse sequencing result for Patient 2 with c. $978 \mathrm{G}>$ A mutation (R269H). C) Patient 3 with c1493 A>T mutation (S498L). resulting in proper postprandial blood glucose (3.4 mmol/L).

\section{Mutation analysis}

As shown in Table 1 \& Figure 2, S498L mutation was detected in Patient 1 and 3. Missense mutation of R269H was detected in Patient 2. For patient 1, genotype of parents was normal indicating that the S498L mutation was de novo. As for Patient 2, blood sample of mother was not available and we collected samples for father and grandmother. They had normal genotype, which suggested the mutation inherited from mother or was de novo. Blood samples of parents of Patient 3 were not available thus it was difficult to determine the origin of mutation. Mutations in S498L and R269H was reported in previous studies $[9,10]$ and protein function prediction suggested highly conserved and pathogenesis mutation, indicating functional significant residues.

\section{Discussion}

In our research, clinical manifestation was heterogenous in regard of age of onset and severity. The mean presentation age was 6.0 months and mean birth weight was $3.15 \mathrm{~kg}$ without macrosomia. They also presented asymptomatic hyperammonemia. Except for persistent HIHA, three patients had common clinical manifestation of convulsion and neurodevelopmental damage. Mutation analysis revealed amino acid position mutation of S498L in patient 1 and 3 while R269H was found in patient 2 .
In recent years, some articles reported mutation in exon of GLUD1 in GDH-CHI children, of which the amino acid position includes S217C, H262Y, R269H, H315Y, Y319H, N410I, N410D, R443W, I444M, S445L, D451V, N463Y, S498L, A500T, H507Y [4,7-11,13-15] etc. Among more than ten kinds of mutation location, $\mathrm{R} 269 \mathrm{H}$ in exon 7 was the most commonly seen and was highly conserved among species, indicating functional important residue. In Chinese population, $\mathrm{ABCC} 8$ and KCNJ11 are the most common mutation genes in CHI [16]. Relatively fewer cases of GLUD1 mutation was reported in Chinese population. During past decades, less than 10 cases reported GLUD1 mutation in Chinese children $[8,10,13,17,18]$. In our study, patient 2 had arginine to histidine substitution at position 269 within the catalytic domain of exon 7, which was one of common mutation site of GLUD1. We detected mutation of adenosine to thymine at position 1493 resulting amino acid change of serine to leucine at position 498 within GTP binding domain in exon 11 of patient 1 and 3. From our point of view, it was suggested mild hypoglycemia at the early stage might lead to delay diagnosis of GDH-CHI as well as 
the development of mental retardation later. Therefore, it is of great importance for early recognition and gene analysis and in $\mathrm{CHI}$ patients. In addition, oral leucine tolerance test is helpful for diagnosis.

It was noteworthy that higher frequency of neuro developmental disorder, especially seizure and learning disability, was reported in GLUD1 mutation than other genes $[2,4,19]$. Pyramidal signs and dystonia were also reported in some patients [19]. To be more specifically, recent studies reported mutation in exon 6 and 7 increased the risk of childhood onset epilepsy [10]. Some researcher explained that overactivity of GDH disturbed the balance of two neurotransmitters (glutamine andgamma-aminobutyric acid) levels in cerebral spinal fluid, which played major roles in brain development [19]. What's more, hyperammonemia and hypoglycemia might also be involved in neurological impairment. Recent research reported sirtuin 4 (SIRT4) inhibited GDH in mitochondrial of glia cell, resulting in down regulation of gliogenesis [20]. It might be part of pathological mechanism for neurodevelopmental disorder in GDH-CHI patients, but further study remained in need to explore the detailed neurological phenotype and genotype relation. For patient 1 and 2, due to delayed diagnosis of HIHA, they had neurodevelopmental disorder several years later during infancy. Patient 2 presented convulsion but dynamic EEG revealed normal, with $\mathrm{R} 269 \mathrm{H}$ substitution at exon 7, suggesting significant necessity for follow-up of epilepsy. Defect of brain development was found in patient 3 but presence of HIHA was as short as one week. In our view, GLUD1 mutation might not sufficient to explain the severity of brain damages, including communicating hydrocephalus and right frontal subdural effusion. Further examination should be done to differentiated other possibility for severe brain damage for him. Some research reported neurodevelopment disorder could relieve as they grew up with well-controlled diet and blood glucose [21-23]. Thus, neurodevelopmental symptoms should be focused and monitor during long-term follow-up.

Treatment for $\mathrm{CHI}$ can be divided into two parts: elevation of blood glucose level and decrease serum insulin. For hypoglycemia, intravenous glucose therapy was usually required to maintain plasma glucose in a normal range, especially when acute severe hypoglycemia episodes occurred. Dietary therapy consisting of low leucine and high carbohydrate is helpful to reduce both the frequency of hypoglycemic episodes and requirement for intravenous glucose. For patients with mild disease, appropriate diet could be enough for glucose control. What's more, fortification of human milk with adequate protein is needed for growth for infants aged 0 to 12 months [24]. For reduction of serum insulin, typical pharmacological therapies included diazoxide, octreotide and glucagon. Diazoxide, a K-ATP channel agonist inhibiting release of insulin from pancreas, is the first-line agent for CHI patients. Inspiringly, most patients with GLUD1 mutation were responsive to diazoxide both in Chinese population and other ethnic groups without K-ATP channel mutations $[2,16,17]$. In our research, for patient 1 and 2 , we decided dose gradient leucine diet to determine appropriate ratio of protein and carbohydrate, which also indicating dose dependent effect for leucine induced insulin secretion. For patient 1 and 3, diazoxide was also used and dosage was monitored based on blood glucose. Blood glucose was under control and frequency for convulsion decreased for all three patients. Thus, we suggested protein-limited diet to be initial treatment for GDH-CHI patients and diazoxide could start for better glucose control. Pharmacologic and dietary therapy are often successful for glucose control for GDH-CHI patient. Followup study for these three patients are undergoing to evaluate the treatment outcome in Chinese population.

In conclusion, we detected GLUD1 mutation in three CHI patients, which improved the genotype-phenotype knowledge for better prognosis and treatment for Chinese population. Overall, early diagnosis, evaluation and appropriate management are essential to avoid the neurodevelopmental consequences including epilepsy and learning disabilities for GDH-CHI children. Genetic analysis and counsel should be conducted early for both affected and suspected patients as well as their pedigree.

\section{Acknowledgment}

The authors thank all colleagues of the department of endocrinology for meticulous diagnosis and care for three patients. The authors also thank the patients and their families participated in the study for their continuous support.

\section{Funding Source}

The study was supported by National Key Research and Development Program of China (No. 2016YFA0101002), National Natural Science Foundation of China (NSFC) (No. 81570715), Novo Nordisk - Union Diabetes Research Talent Fund, and PUMCH-UCSF Joint Funding Program (PUMCH-UCSF RT201501).

\section{Disclosure}

None of the authors have any potential conflicts of interests associated with this research.

\section{References}

1. Rahman SA, Nessa A, Hussain K (2015) Molecular mechanisms of congenital hyperinsulinism. J Mol Endocrinol 54(2) R119-R129.

2. Stanley CA (2016) Perspective on the Genetics and Diagnosis of Congenital Hyperinsulinism Disorders. J Clin Endocrinol Metab 101(3): 815-826.

3. Snider KE, Becker S, Boyajian L, Shyng SL, MacMullen C, et al. (2013) Genotype and phenotype correlations in 417 children with congenital hyperinsulinism. J Clin Endocrinol Metab 98(2): E355-E363.

4. Kapoor RR, Flanagan SE, Fulton P, Chakrapani A, Chadefaux B, et al. (2009) Hyperinsulinism-hyperammonaemia syndrome: novel mutations in the GLUD1 gene and genotype-phenotype correlations. Eur J Endocrinol 161(5): 731-735.

5. Kibbey RG, Choi CS, Lee HY, Cabrera O3, Pongratz RL, et al. (2014) Mitochondrial GTP insensitivity contributes to hypoglycemia in hyperinsulinemia hyperammonemia by inhibiting glucagon release. Diabetes 63(12): 4218-4229. 
6. Kapoor RR, Flanagan SE, Arya VB, Shield JP, Ellard S, et al. (2013) Clinical and molecular characterisation of 300 patients with congenital hyperinsulinism. Eur J Endocrinol 168(4): 557-564.

7. Aso K, Okano Y, Takeda T, Sakamoto O, Ban K, et al. (2011) Spectrum of glutamate dehydrogenase mutations in Japanese patients with congenital hyperinsulinism and hyperammonemia syndrome. Osaka City Med J 57(1): 1-9.

8. Fang C, Ding X, Huang Y, Huang J, Zhao P, et al. (2016) A novel mutation in the glutamate dehydrogenase (GLUD1) of a patient with congenital hyperinsulinism-hyperammonemia (HI/HA). J Pediatr Endocrinol Metab 29(3): 385-388.

9. Faletra F, Athanasakis E, Morgan A , Biarnés X, Fornasier F, et al. (2013) Congenital hyperinsulinism: clinical and molecular analysis of a large Italian cohort. Gene 521(1): 160-165.

10. Sang Y, Xu Z, Liu M, Yan J, Wu Y, et al. (2014) Mutational analysis of ABCC8, KCNJ11, GLUD1, HNF4A and GCK genes in 30 Chinese patients with congenital hyperinsulinism. Endocr J 61(9): 901-910.

11. Odom J, Gieron-KM, Shulman D, Newkirk P, Prijoles E, et al. (2016) A novel mutation in GLUD1 causing hyperinsulinism-hyperammonemia in a patient with high density of homozygosity on microarray: a case report. J Med Case Rep 10: 25.

12. De Leon DD, Stanley CA (2007) Mechanisms of Disease: advances in diagnosis and treatment of hyperinsulinism in neonates. Nat Clin Pract Endocrinol Metab 3(1): 57-68.

13. Xu ZD, Yu HF, Sang YM, Zhang YN, Yan J, et al. (2013) ABCC8, KCNJ11 and GLUD1 gene mutation analysis in congenital hyperinsulinism pedigree. Zhonghua Yi Xue Za Zhi 93(14): 1089-1092.

14. de Las HJ, Garin I, de Nanclares GP, Aguayo A, Rica I, et al. (2010) Familial hyperinsulinism-hyperammonemia syndrome in a family with seizures: case report. J Pediatr Endocrinol Metab 23(8): 827-830.

15. Sang YM, Ni GC, Liu GQ, Liu M, Gu Y (2010) Mutation analysis of the GLUD1 gene in patients with glutamate dehydrogenase congenital hyperinsulinism. Zhonghua Yi Xue Yi Chuan Xue Za Zhi 27(5): 493-496.
16. Weiyan W, Sun Y, Zhao WT, Wu T, Wang L, et al. (2017) Congenital Hyperinsulinism in china: a review of Chinese literature over the past 15 years. J Clin Res Pediatr Endocrinol 9(3): 194-201.

17. Fan ZC, Ni JW, Yang L, Hu LY, Ma SM, et al. (2015) Uncovering the molecular pathogenesis of congenital hyperinsulinism by panel gene sequencing in 32 Chinese patients. Mol Genet Genomic Med 3(6): 526536.

18. Diao C, Chen S, Xiao X, Wang T, Sun X, et al. (2010) Two unrelated Chinese patients with hyperinsulinism /hyperammonemia (HI/ HA) syndrome due to mutations in glutamate dehydrogenase gene. J Pediatr Endocrinol Metab 23(7): 733-738.

19. Bahi-BN, Roze E, Dionisi C, Escande F, Valayannopoulos V, et al. (2008) Neurological aspects of hyperinsulinism-hyperammonaemia syndrome. Dev Med Child Neurol 50(12): 945-949.

20. Komlos D, Mann KD, Zhuo Y, Ricupero CL, Hart RP, et al. (2013) Glutamate dehydrogenase 1 and SIRT 4 regulate glial development. Glia 61(3): 394-408.

21. Mazor-AK, Gillis D, Lobel D, Hirsch HJ, Pinhas-HO, et al. (2007) Long-term neuro developmental outcome in conservatively treated congenital hyperinsulinism. Eur J Endocrinol 157(4): 491-497.

22. Avatapalle HB, Banerjee I, Shah S, Pryce M, Nicholson J, et al. (2013) Abnormal Neurodevelopmental Outcomes are Common in Children with Transient Congenital Hyperinsulinism. Front Endocrinol (Lausanne) 4:60.

23. Su C, Gong C, Sanger P, Li W, Wu D, et al. (2014) Long-term follow-up and mutation analysis of 27 chinese cases of congenital hyperinsulinism. Horm Res Paediatr 81(3): 169-176.

24. Edwards TM, Spatz DL et al. (2014) Congenital hyperinsulinism: exclusive human milk and breastfeeding. Adv Neonatal Care 14(4): 262-266.

\section{Your next submission with Juniper Publishers will reach you the below assets}

- Quality Editorial service

- Swift Peer Review

- Reprints availability

- E-prints Service

- Manuscript Podcast for convenient understanding

- Global attainment for your research

- Manuscript accessibility in different formats ( Pdf, E-pub, Full Text, Audio)

- Unceasing customer service

Track the below URL for one-step submission https://juniperpublishers.com/online-submission.php 